\title{
Perinatal lung function and invasive antenatal procedures
}

\author{
B Yüksel, A Greenough, S Naik, P Cheeseman, K H Nicolaides
}

\begin{abstract}
Background - Second trimester amniocentesis has been associated with an excess of perinatal lung function abnormalities. Early amniocentesis might have a similar adverse effect, as could other invasive investigations carried out in the first trimester.
\end{abstract}

Methods - Plethysmographic measurements of thoracic gas volume (TGV) and airway resistance (Raw), from which specific conductance (sGaw) was calculated, were made in the perinatal period in non-sedated infants. In addition, functional residual capacity (FRC) was measured using a helium gas dilution technique. Measurements were made in 47 infants whose mothers had undergone early amniocentesis, 19 whose mothers had undergone chorion villus sampling, and 25 controls whose mothers had undergone no invasive antenatal procedures.

Results - The infants of mothers who had undergone early amniocentesis had higher TGV (95\% CI -6.3 to $1.1 \mathrm{ml} / \mathrm{kg})$ and Raw values $\left(95 \% \mathrm{CI}-10.68\right.$ to $\left.-5.23 \mathrm{~cm} \mathrm{H} \mathrm{H}_{2} \mathrm{O} / 1 / \mathrm{s}\right)$ and lower sGaw (0.11 to $0.841 / \mathrm{cm} \mathrm{H}_{2}$ O.s) and FRC $(-5.17$ to $-0.87 \mathrm{ml} / \mathrm{kg})$ values than the controls. Infants whose mothers had undergone chorion villus sampling also differed significantly from the controls with higher Raw $\left(-7.59\right.$ to $-1.99 \mathrm{~cm} \mathrm{H} \mathrm{H}_{2} \mathrm{O}$ I $1 / s)$ and lower sGaw values (0.11 to $0.241 /$ cm $\mathrm{H}_{2}$ O.s), and had lower Raw values than those in the early amniocentesis group (not significant). Logistic regression analysis, taking into account possible risk factors for abnormal lung function, showed that the procedures performed in the first trimester were independently associated with a high airways resistance.

Conclusion - These results suggest that invasive procedures performed in the first trimester of pregnancy have an adverse effect on perinatal lung function.

(Thorax 1997;52:181-184)

Keywords: amniocentesis, chorion villus sampling, infant lung function.

Mid trimester amniocentesis has been associated with lung function abnormalities in the perinatal period including a reduction in crying vital capacity, ${ }^{1}$ lower dynamic compliance, and a tendency to a higher resistance. ${ }^{2}$ Such lung function abnormalities suggest that amniocentesis adversely impacts on lung growth and development. There are several possible mechanisms for such an effect. One possibility is a reduction in amniotic fluid volume, and this is supported by the finding of suboptimal lung growth following amniocentesis in an animal model. ${ }^{3}$ Data from pregnancies complicated by preterm rupture of the membranes would suggest that very early removal of amniotic fluid, as occurs during first trimester or early amniocentesis, would be particularly deleterious. A second possible mechanism is the inhibition of fetal breathing movements which are essential for lung growth. ${ }^{4}$ Breathing movements have been shown to decrease for up to 48 hours following amniocentesis ${ }^{5}$ which may be the result of the invasive procedure increasing uterine activity; ${ }^{6}$ this could also result from chorion villus sampling. It therefore seems likely that both early amniocentesis and chorion villus sampling could adversely affect perinatal lung function and this study was undertaken to test this hypothesis

\section{Methods}

SUBJECTS

Infants delivered at King's College Hospital whose mothers had undergone either early amniocentesis or chorion villus sampling (subjects) or no invasive antenatal procedure (controls) were eligible for entry into the study if they developed no respiratory problems in the perinatal period nor required admission to the neonatal intensive care unit. They were identified from the Harris Birthright records and daily scrutiny of the computerised labour ward records by a researcher who was unaware of the infant's outcome other than that he or she was a liveborn singleton. Infants were recruited if their parents gave informed written consent and the study was also approved by the ethics committee of King's College Hospital. Recruitment was planned to continue until there were at least 25 infants in each group (see trial size).

\section{STUDY DESIGN}

Infants and their mothers attended the Paediatric Respiratory Laboratory before discharge from the postnatal ward. Infants were studied at least 12 hours from birth and 24 hours if they had been delivered by caesarean section to allow sufficient time for lung fluid clearance which could otherwise have affected lung function. ${ }^{78}$ Thoracic gas volume (TGV), airway resistance (Raw), and functional residual capacity (FRC) were measured during quiet sleep approximately one hour after a feed. No
Revised version received
9 August 1996

Accepted for publication

15 August 1996 
sedation was given. Specific conductance (sGaw) was calculated from TGV and Raw.

LUNG FUNCTION MEASUREMENTS

TGV and Raw were measured using a whole body plethysmograph (Hammersmith Hospital Infant Whole Body Plethysmograph, Department of Medical Engineering, Hammersmith Hospital) with a total volume of 90 litres. The infant breathed through a face mask which was connected to the rebreathing bag via a heated pneumotachograph and was sealed around the infant's nose and mouth using silicone putty to ensure an airtight seal. Breathing was through a heated, humidified rebreathing system to avoid box pressure changes due to the heating and cooling of respired gas. Box and mouth pressure were measured using Validyne pressure transducers (Model MP 45) range $\pm 2 \mathrm{~cm} \mathrm{H}_{2} \mathrm{O}$ and $\pm 50 \mathrm{~cm} \mathrm{H}_{2} \mathrm{O}$, respectively. The pneumotachograph was attached to a differential pressure transducer (model MP 45 range $\pm 2 \mathrm{~cm} \mathrm{H}_{2} \mathrm{O}$ ); the flow signal was integrated to volume using a Validyne FV 154 volume integrator. The analogue signals from the transducers were fed into a Validyne CD 18 carrier demodulator (amplifier) and output on to an ultraviolet chart recorder for later analysis. TGV was measured at the end of a normal inspiration, tidal volume was subtracted to give the final TGV result. Occlusion at the end of inspiration rather than the end of expiration was used as, using the latter technique, TGV is more likely to be overestimated. ${ }^{9}$ Raw was calculated at two thirds of maximum inspiratory flow by the techniques of Dubois et al suitably modified for infants. ${ }^{1011}$ TGV was calculated from five breaths during occlusion; at least five separate occlusions were made. Raw was calculated from at least 10 breaths. All measurements (TGV and Raw) were corrected for the apparatus dead space including the face mask $(15 \mathrm{ml})$ and resistance $\left(8 \mathrm{~cm} \mathrm{H}_{2} \mathrm{O} / 1 / \mathrm{s}\right.$ measured at flows of $5-151 / \mathrm{min}$ ). Traces were analysed without knowledge of the clinical details. The plethysmograph was calibrated before and after each measurement by inserting into the plethysmograph a quantity of bags of normal saline of similar weight to the infant and recording the change in box pressure in response to a change in volume (10 times) of $5,10,15$ and $20 \mathrm{ml}$. The flow signal was calibrated with a rotameter using flows of $0-121 / \mathrm{min}$. The volume signal was calibrated by moving 30 and $60 \mathrm{ml}$ of air through the pneumotachograph from a syringe at a frequency equivalent to the infant's respiratory rate. Mouth pressure was calibrated using a standard water manometer over a range of $0-24 \mathrm{~cm} \mathrm{H}_{2} \mathrm{O}$.

After completion of the measurements of TGV and Raw the infant's face mask was connected to a water sealed spirometer (Gould Pulmonet III) for the measurement of FRC by helium gas dilution. The spirometer has an internal carbon dioxide absorber, an adjustable oxygen supply, and a total volume of 6 litres. The water sealed spirometer incorporates a digital display of FRC which was recorded on the trace at 15 second intervals. Equilibration was assumed to have occurred when there had been no change in the FRC readout over a 30 second period. All the FRC traces were coded and then analysed without knowledge of the clinical details. From the trace, the equilibration point and end expiratory level were determined and FRC thus calculated. The results were then converted to body temperature, pressure, and saturation conditions. The accuracy of the spirometer was checked daily with a one litre calibrated syringe (Vitalograph, Buckingham, UK).

\section{STUDY POWER}

The variation in airways resistance results from a previous study ${ }^{12}$ meant that recruitment of 25 infants into each group would allow us to detect with $90 \%$ power at the $5 \%$ level a difference in airway resistance of $5 \mathrm{~cm} \mathrm{H}_{2} \mathrm{O} / 1 / \mathrm{s}$.

\section{ANALYSES}

Differences between groups were assessed for statistical significance using the Kruskal-Wallis or $\chi^{2}$ test as appropriate. The $95 \%$ confidence intervals of the differences of the means were also calculated. Logistic regression analysis was performed to determine whether an increase in Raw - that is, greater than the median value - was independently related to first trimester procedures; other risk factors which were assessed were maternal age, parental smoking, family history of atopy, caesarean section, and male sex.

\section{Results}

\section{PATIENTS}

Parents of 100 eligible subjects were approached: 18 parents declined to take part in the study, four infants did not attain quiet sleep, and 12 others could only be studied outside the perinatal period. Parents of 35 possible controls were approached: eight parents declined to take part in the study and two infants did not attain quiet sleep. Unfortunately, by chance, the proportion of mothers who delivered at King's College Hospital who underwent early amniocentesis was much greater than those who underwent chorion villus sampling so we halted the trial after recruiting 25 controls. Data from 47 infants whose mothers had undergone early amniocentesis, 19 chorion villus sampling and 25 controls are reported (table 1), some of which have been reported previously. ${ }^{12} 13$ The mothers who had undergone either early amniocentesis or chorion villus sampling were older than the controls $(p<0.001)$, the only other significant difference between the groups being that the infants in the chorion villus sampling and early amniocentesis groups were measured at a slighter older postnatal age than the controls $(\mathrm{p}<0.05)$. None of the infants studied had any congenital malformation or chromosomal abnormality.

The results of the early amniocentesis group differed significantly from the controls with respect to TGV $(\mathrm{p}<0.05)$, Raw $(\mathrm{p}<0.001)$, 
Table 1 Maternal and infant characteristics expressed as median (range) or $n$ (\%)

\begin{tabular}{llll}
\hline & $\begin{array}{l}\text { Early amniocentesis } \\
(n=47)\end{array}$ & $\begin{array}{l}\text { Chorion villus sampling } \\
(n=19)\end{array}$ & $\begin{array}{l}\text { Controls } \\
(n=25)\end{array}$ \\
\hline Maternal age (years) & $38(23-45)(\mathrm{p}<0.001)$ & $37(29-45)(\mathrm{p}<0.001)$ & $32(20-41)$ \\
Parental smoking & $11(23)(\mathrm{p}=0.24)$ & $5(26)(\mathrm{p}=0.22)$ & $3(12)$ \\
Family history of atopy & $18(38)(\mathrm{p}=0.22)$ & $7(37)(\mathrm{p}=0.35)$ & $7(24)$ \\
Caesarean section & $18(38)(\mathrm{p}=0.38)$ & $3.54(2.91-4.96)(\mathrm{p}=0.04)$ & $3.32(2.5-4.39)$ \\
Birthweight (kg) & $3.42(1.82-4.3)(\mathrm{p}=0.72)$ & $10(53)(\mathrm{p}=0.97)$ & $13(52)$ \\
Male sex & $18(38)(\mathrm{p}=0.26)$ & $39(37-42)(\mathrm{p}=0.89)$ & $39(37-41)$ \\
Gestational age (weeks) & $40(34-42)(\mathrm{p}=0.62)$ & $3(1-6)(\mathrm{p}=0.02)$ & $2(1-4)$ \\
Postnatal age (days) & $2(1-7)(\mathrm{p}=0.27)$ & $4(21)(\mathrm{p}=0.34)$ & $6(24)$ \\
Breastfeeding & $14(32)(\mathrm{p}=0.80)$ & & \\
\hline
\end{tabular}

Significance levels are shown for comparisons between the early amniocentesis or chorion villus sampling groups versus controls.

sGaw ( $\mathrm{p}<0.001)$, and FRC $(\mathrm{p}<0.05)$ (table 2). The results of the chorion villus sampling group differed significantly from the controls with respect to Raw $(\mathrm{p}<0.05)$ and $\mathrm{sGaw}(\mathrm{p}<0.001)$ only. The results of these two groups did not differ significantly from one another. Logistic regression analysis showed that first trimester procedures were independently associated with an increase in Raw $\left(>26 \mathrm{~cm} \mathrm{H}_{2} \mathrm{O} / \mathrm{l} / \mathrm{s} ; \mathrm{p}<0.05\right.$; table 3).

\section{Discussion}

Both the early amniocentesis and chorion villus sampling groups had increased airway resistance compared with the controls. After amniocentesis in the monkey, changes occurred in the lungs of the fetus regardless of the amount of fluid removed or even if the membranes were simply punctured and no fluid removed. ${ }^{14}$ We were therefore not surprised

Table 2 Respiratory function test results expressed as median (range) and mean (95\% confidence intervals of the differences of the means)

\begin{tabular}{|c|c|c|c|}
\hline & $\begin{array}{l}\text { Early amniocentesis } \\
(E A) \\
(n=47)\end{array}$ & $\begin{array}{l}\text { Chorion villus sampling } \\
\text { (CVS) } \\
(n=19)\end{array}$ & $\begin{array}{l}\text { Controls } \\
(n=25)\end{array}$ \\
\hline \multirow[t]{2}{*}{$\mathrm{TGV}(\mathrm{ml} / \mathrm{kg})$} & $\begin{array}{l}35(23-44) \\
33\end{array}$ & $\begin{array}{l}33(23-42) \\
33\end{array}$ & $\begin{array}{l}32(20-38) \\
31\end{array}$ \\
\hline & \multicolumn{2}{|c|}{$\begin{array}{l}(-1.32 \text { to } 4.36) \quad(-5.16 \text { to } 0.76) \\
\text { EA versus controls }-6.3 \text { to }-1.1\end{array}$} & \\
\hline \multirow[t]{2}{*}{$\operatorname{Raw}\left(\mathrm{cm} \mathrm{H}_{2} \mathrm{O} 1 / \mathrm{s}\right)$} & $\begin{array}{l}30(16-45) \\
29\end{array}$ & $\begin{array}{l}27(16-32) \\
26\end{array}$ & $\begin{array}{l}21(15-31) \\
21\end{array}$ \\
\hline & \multicolumn{2}{|c|}{$\begin{array}{l}(-0.04 \text { to } 6.38) \\
\text { EA versus controls }-10.68 \text { to }-5.23\end{array}$} & \\
\hline \multirow[t]{2}{*}{ sGaw $\left(1 / \mathrm{cm} \mathrm{H}_{2} \mathrm{O} . \mathrm{s}\right)$} & $\begin{array}{l}0.309 \\
0.333\end{array}$ & $\begin{array}{l}0.302(0.21-0.65) \\
0.348\end{array}$ & $\begin{array}{l}0.447(0.317-0.707) \\
0.510\end{array}$ \\
\hline & \multicolumn{2}{|c|}{$\begin{array}{c}(-0.07 \text { to } 0.04) \quad(-0.69 \text { to } 0.25) \\
\text { EA versus controls } 0.11 \text { to } 0.24\end{array}$} & \\
\hline \multirow[t]{2}{*}{ FRC (ml/kg) } & $\begin{array}{l}26(20-40) \\
29\end{array}$ & $\begin{array}{l}29(19-38) \\
27\end{array}$ & $\begin{array}{l}27(18-34) \\
26\end{array}$ \\
\hline & \multicolumn{2}{|c|}{$\begin{array}{ll}(-0.18 \text { to } 4.86) & (-3.17 \text { to } 1.82) \\
\text { EA versus controls } & -5.17 \text { to }-0.87\end{array}$} & \\
\hline
\end{tabular}

$\mathrm{TGV}=$ thoracic gas volume; Raw $=$ airway resistance; $\mathrm{sGaw}=$ specific conductance $\mathrm{FRC}=$ functional residual capacity.

Table 3 Odds ratio and 95\% confidence intervals for increased airway resistance (Raw)

\begin{tabular}{lll}
\hline Risk factor & Odds ratio & $95 \%$ CI \\
\hline First trimester procedures & 5.93 & 1.17 to 30.17 \\
Maternal age & 1.08 & 0.93 to 1.26 \\
Parental smoking & 1.53 & 0.66 to 3.5 \\
Family history of atopy & 2.09 & 0.34 to 12.7 \\
Caesarean section & 1.9 & 0.09 to 40.8 \\
Male sex & 0.69 & 0.10 to 4.79 \\
Birthweight & 0.44 & 0.16 to 1.19 \\
Postnatal age & 1.53 & 0.66 to 3.5 \\
\hline
\end{tabular}

that the lung function results of infants whose mothers had undergone either of the first trimester invasive procedures differed significantly from those of the controls.

Purely by chance, our groups did not contain similar numbers of patients. The infants studied were only preselected by place of delivery and the consent of their mothers to take part in the study, and remained on the postnatal ward for at least 12 hours. Unfortunately we were only able to recruit 19 infants to the chorion villus sampling group which reduced the power of the study from $90 \%$ to $80 \%$. The only significant difference between the three groups was that the infants whose mothers had undergone chorion villus sampling and early amniocentesis were measured at an older age within the perinatal period than the controls. There were trends in other characteristics which could have affected lung function, particularly the proportions of subjects who had a positive family history of atopy or whose parents smoked. Logistic regression analysis, however, showed that the first trimester procedures were significantly associated with an abnormal increase in airways resistance independent of other risk factors.

In an animal mode ${ }^{14}$ amniocentesis resulted in a reduction in alveolar diameter, alveolar duct diameter, and respiratory bronchiolar length; however, the same size amniocentesis needle was used as in clinical practice and thus may have led to greater damage than would occur in clinical trials. The reduction in alveolar duct diameter might increase resistance and a trend towards an increase in total pulmonary resistance has been noted following second trimester amniocentesis. ${ }^{2}$ We have now shown an increase in resistance of middle to large airways and this remained significant when a subanalysis was performed on matched groups. None of the infants studied was symptomatic or had required admission to the Neonatal Intensive Care Unit (NICU) for respiratory problems, thus this abnormality seems unlikely to reflect bronchoconstriction but rather abnormal growth of the airways.

Overall, the infants whose mothers had undergone early amniocentesis had significantly higher TGV and lower FRC than the infants in the control group. Delay in clearance of lung fluid can result in a low FRC:TGV ratio, ${ }^{7}$ but this is unlikely to be the explanation for our findings as there were no significant differences in the rate of caesarean section or timing of respiratory measurements between the infants in the early amniocentesis group 
and controls. The higher TGV and lower FRC in the early amniocentesis group, combined with the higher Raw in that group, suggests that the lung volume abnormalities might be due to gas trapping. To measure FRC we used a six litre spirometer as this same system has been previously used in small babies with reliable results, even in those born very prematurely. ${ }^{15-17}$ Indeed, in this study we did find significant differences in lung volume between the groups using this technique. The differences in lung volume between the groups, however, although statistically significant, were small, not present in the subanalysis, and unlikely to be of clinical relevance.

All three groups tested had a relatively low incidence of smoking and this is likely to be a reflection of the maternal age of the population we tested. ${ }^{18}$ It is older mothers, however, who are most likely to undergo invasive antenatal investigation for fetal chromosomal abnormalities, thus our control group does seem appropriate. Comparison with such controls shows that infants whose mothers had undergone both early amniocentesis and chorion villus sampling had increased airways resistance which was independent of other risk factors. We therefore conclude that first trimester procedures may be associated with perinatal lung function abnormalities. Unfortunately, after the first weeks of life sedation is required to perform plethysmographic measurements and such a procedure is frequently declined by parents of asymptomatic infants. We are therefore unable to comment as to whether the abnormalities identified by plethysmographic measurements in the first week of life are transient. Interestingly, however, such infants are more likely to have respiratory symptoms in the first year of life, perhaps suggesting an ongoing problem. ${ }^{19}$

Dr Yüksel was supported by the Medical Research Council and Dr Naik by the Children Nationwide Medical Research Fund. We thank Ms Sue Williams for secretarial assistance.
1 Vyas H, Milner AD, Hopkins IE. Amniocentesis and fetal lung development. Arch Dis Child 1982;57:627-8.

2 Milner AD, Hoskyns EW, Hopkin IE. The effects of mid trimester amniocentesis on lung function in the perinatal period. Eur f Pediatr 1992;151:458-60.

3 Hislop AA, Fairweather DVI. Amniocentesis and lung growth. An animal experiment with clinical implications. Lancet 1982;ii:1271-2.

4 Wigglesworth JS, Desai R. Effect on lung growth of cervical cord section in the rabbit fetus. Early Hum Dev 1979;3 $51-6$.

5 Manning FA, Platt LD, Lemay M. Effect of amniocentesi on fetal breathing movements. BMF 1977;2:1582-3

6 Schwarz RH. Amniocentesis. Clin Obstet Gynecol 1975;18: $1-22$

7 Boon AW, Ward-McQuaid JMC, Milner AD, Hopkin IE. Thoracic gas volume, helium functional residual capacity and airtrapping in the first six hours of life. The effect of oxygen administration. Early Hum Dev 1981;5:157-66.

8 Boon AW, Milner AD, Hopkin IE. Lung volumes and lung mechanics in babies born vaginally and by elective and emergency lower segmental caesarean section. I Pediatr 1988;98:812-5.

9 Yuksel B, Greenough A. Measurement of thoracic gas volume in patients born prematurely: should occlusion be made at end-inspiration or end-expiration? Pediatr Pulmonol 1994;18:295-8.

10 DuBois AB, Botelho SY, Bedell GN, Marshall R, Comrie $\mathrm{JH}$. A rapid plethysmographic method for measuring thoracic gas volume: a comparison with a nitrogen washout
method for measuring functional residual capacity in normethod for measuring functional residual cap

11 Dubois AB, Botelho SY, Comree JH. A new method fo measuring airway resistance in man using a body plethysmograph: values in normal subjects and in patien with respiratory disease. 7 Clin Invest 1956;35:327-32.

12 Yüksel B, Greenough A. Functional residual capacity to thoracic gas volume (FRC:TGV) ratio in healthy neonates. Respir Med 1995;89:429-33.

13 Yüksel B, Greenough A, Giffin F, Nicolaides KH. Tida breathing parameters in the first week of life and subsequent cough and wheeze. Thorax 1996;51:815-8.

14 Hislop A, Fairweather DVI, Blackwell RJ, Howard S. The effect of amniocentesis and drainage of amniotic fluid on lung development of Macaca fascicularis. $\mathrm{Br} \mathcal{F}$ Obstet Gynaecol 1984;91:835-42.

15 Yüksel B, Greenough A, Green S. Lung function abnormalities at six months of age after neonatal intensive care. Arch Dis Child 1991;66:472-6.

16 Yüksel B, Greenough A Neonatal respiratory distress and lung function at follow-up. Respir Med 1991;85:235-7.

17 Yüksel B, Greenough A. Neonatal respiratory support and lung function abnormalities at follow-up. Respir Med 1992; 86:97-100.

18 Yüksel B, Greenough A, Dobson P, Nicolaides KH. Advanced maternal age and smoking: risk factors for admission to a neonatal intensive care unit. $\mathcal{F}$ Perinat Med 1996;24:397-403.

19 Naik S, Greenough A, Itakura Y, Yüksel B, Nicolaides KH. Perinatal lung function measurement and prediction of respiratory morbidity in infants. Early Hum Dev 1996 (abstract in press). 